\title{
Correction to: Photobiomodulation versus light-emitting diode (LED) therapy in the treatment of temporomandibular disorder: study protocol for a randomized, controlled clinical trial
}

\author{
Luciana G. Langella, Paula F. C. Silva, Larissa Costa-Santos, Marcela L. L. Gonçalves, Lara J. Motta, \\ Alessandro M. Deana, Kristianne P. S. Fernandes, Raquel A. Mesquita-Ferrari and Sandra Kalil Bussadori ${ }^{*}$
}

Correction to: Trials (2018) 19:71

https://doi.org/10.1186/s13063-018-2444-7

After publication of our article [1] some questions were raised by a reader. We are grateful to the Editors-in-Chief for inviting Anne-Marie Glenny (Division of Dentistry, University of Manchester) to assess these questions, our responses and our published article. As a result we are publishing this Erratum to clarify various points. These are as follows:

- We appreciate that the title of our article does not clearly describe our protocol. Instead of

"Photobiomodulation versus light-emitting diode (LED) therapy in the treatment of temporomandibular disorder: study protocol for a randomized, controlled clinical trial" a more appropriate title would be: "Photobiomodulation with laser versus photobiomodulation with lightemitting diode (LED) in the treatment of temporomandibular disorder: study protocol for a randomized, controlled clinical trial";

- We would like to add that the sequence generation to randomize patients will be computer generated;

- We would like to make it clear that our primary outcome is pain, evaluated with a visual analog scale (VAS).
Received: 30 November 2018 Accepted: 30 November 2018

Published online: 24 December 2018

References

1. Langella et al. Photobiomodulation versus light-emitting diode (LED) therapy in the treatment of temporomandibular disorder: study protocol for a randomized, controlled clinical trial. 2018;19:71. https://doi.org/10.1186/ s13063-018-2444-7.

* Correspondence: sandra.skb@gmail.com

Nove de Julho University, 235/249 Vergueiro Street, Liberdade, São Paulo 01504-001, Brazil 